\title{
Hacia la Biblioteca Digital Universal de Historia Natural
}

\author{
A. G. Valdecasas, M. Ramos \& I. Morón
}

Entre las varias iniciativas que persiguen el ideal de una Biblioteca Digital Universal una de las más destacadas es la Biodiversity Heritage Library (BHL, http://www.biodiversitylibrary.org/) que desde 2007 está construyendo el sistema de gestión y acceso online a los contenidos especializados que se están digitalizando y que están dedicados principalmente a las publicaciones (artículos en revistas, libros y material de archivo) relacionadas con la Historia Natural.

BHL es un consorcio de varias instituciones de EEUU (la Smithsonian Institution, la Universidad de Harvard o el Jardín Botánico de Missouri, entre otras) y el Natural History Museum de Londres. BHL se ha convertido ya en uno de los pilares de la Encyclopedia of Life (EoL, http://www.eol.org).

En mayo de este año, 26 instituciones Europeas de 14 países se han sumado al proyecto que lleva el acrónimo de BHL-Europe y que ha sido aprobado en el marco del $7^{\circ}$ Programa Marco de la Comisión Europea (Subprograma e-Contents Plus). El Museo Nacional de Ciencias Naturales (CSIC) es el representante español en BHL-Europe.

El objetivo final es permitir a los científicos (profesionales y no profesionales), público en general, agentes políticos y sociales o el mundo de la industria, el acceso libre a una información de primera mano sobre animales y plantas, en cualquier momento, desde cualquier lugar y sin límites.

A través de esta nota queremos llamar la atención a todos los especialistas interesados en la Historia Natural, biólogos, historiadores, bibliotecarios y administradores sobre esta iniciativa y a que se involucren en el prometedor futuro de esta iniciativa mundial, que está abierto a todas las bibliotecas Europeas (tanto públicas como privadas), y, por supuesto, a conocer y hacer uso de su contenido para su propio trabajo.

Contacto en España: Antonio G. Valdecasas (valdeca@mncn.csic.es)

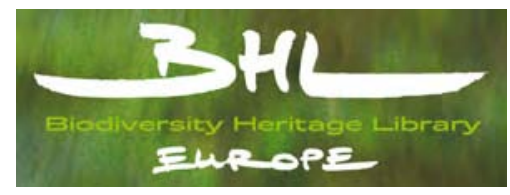

Recibido, 8-VI-2009

Aceptado, 10-VI-2009 Publicado, 29-VI-2009 